\title{
Re-imagining a Nation: The Australian Dictionary of Biography Online
}

\author{
Paul Longley Arthur
}

University of Western Sydney

\section{ABSTRACT}

This essay investigates how the digital medium has recently enabled radical changes in the ways that national biography can be generated and engaged with. It takes the position that national biography, whether or not it sets out to do so, reflects how a nation views itself. The Australian Dictionary of Biography (ADB) has been produced continuously for more than 50 years, and has cumulatively generated a story of a nation. The nature of that collective narrative, however, is not easy to discover. Now, as a result of the ADB's recent adoption of digital formats, the potential for analysis of the biographies it contains has expanded exponentially, offering unprecedented research opportunities for investigating in new ways how the idea of nation itself has evolved in Australia.

Australia is very fortunate to have a national biographical dictionary that is democratic as well as distinguished, one that represents the rich variety of Australian culture. - Dawn Casey ${ }^{1}$

The underlying theme of the mosaic is quite clear: nothing less than the making and re-making of Australia. - Her Excellency Penelope Wensley ${ }^{2}$

I propose the following definition of the nation: it is an imagined political community.... It is imagined because the members of even the smallest nation will never know most of their fellow- members, meet them, or even hear of them, yet in the minds of each lives their communion. - Benedict Anderson $^{3}$ 
The Australian Dictionary of Biography (ADB), with almost 13,000 Australians represented by their biographies gathered within its volumes, ${ }^{4}$ expresses in its physical form something of the sense of communion that Benedict Anderson referred to in his definition of the nation. Brought together in death these people of Australia are arranged alphabetically and grouped in accordance with the time of their influence or dying, decade by decade, rather than through any connection with each other that they may have had in life. Their inclusion in the dictionary as 'significant men and women of this country' ${ }^{5}$ posthumously entitles them to be members of this community and thereby invites connections to be made between their individual stories and with the communal story - the history - of Australia. Although it may not have set out to do so, by telling the stories of individual citizens, the ADB has cumulatively generated a story of a nation. In the words of Gareth Evans, 'The Australian Dictionary of Biography captures the life and times and culture of this country in an absolutely distinctive and irreplaceable way. It is the indispensable record of who we are, and of the characters who have made us what we are'. ${ }^{6}$

The ADB has been produced continuously for more than 50 years, resulting to date in 18 print volumes, plus a supplementary volume and index, published to very high scholarly standards. ${ }^{7}$ In the latter part of this paper I use the example of the $\mathrm{ADB}$, widely recognised in Australia as 'our greatest collective research project in the humanities', ${ }^{8}$ and focus on a specific aspect of the dictionary - its capacity to be representative of one nation's identity and history - to investigate how the digital medium has recently enabled radical changes in the ways that "national biography' ${ }^{\prime 9}$ can be generated and engaged with. At the heart of this change is the new capacity for the dictionary to open itself up to various kinds of digging and delving, vertically and horizontally and from micro to macro scales of exploration and critique. Among the opportunities offered by digitisation is that of investigating in new ways the idea of nation itself as it has evolved in Australia.

The centrality of the interplay between the life stories of individuals and 'the great collective story'10 of a nation, to use Fredric Jameson's term, has been foregrounded repeatedly in recent decades, particularly from postcolonial, feminist and postmodernist perspectives, where the critical focus has been on hierarchies of power and the politics of inclusion/exclusion within national narratives. As Homi Bhabha explains,

Out of many one: nowhere has this founding dictum of the political society of the modern nation - its spatial expression of a unitary people - found a more intriguing image of itself than in those diverse languages of literary 
criticism that seek to portray the great power of the idea of the nation in the disclosure of its everyday life; in the telling details that emerge as metaphors for national life. ${ }^{11}$

In a similar vein, Jameson claims that 'the telling of the individual story and the individual experience cannot but ultimately involve the whole laborious telling of the collectivity itself'. ${ }^{12}$ Focussing his analysis on film and fiction, Graeme Turner asserts that 'the materials for the story, its detailed and individualised representation of life, are drawn from the narrative langue of the culture. This langue is not only linguistic in the narrow sense, it is also ideological.... The language of narrative is "bathed in ideology", in Althusser's phrase'. ${ }^{13}$ In this context then, biography is the ideal vehicle for building a sense of the character of the collective - its identity.

The nature of that 'great collective story', however, is not easy to discover. In fact, in the case of the ADB, with its many thousands of biographies, the sheer scale of the publication has presented a significant barrier to this kind of broad investigative work in the past. Now, as a result of the ADB's recent adoption of digital formats, the potential for analysis of the individual biographies has expanded exponentially, offering unprecedented and seemingly limitless research opportunities and multiple viewing lenses for 'making and re-making' aspects of the Australian story. At the same time, auto/biography itself has undergone a digital revolution through the sudden mass adoption of social media.

What are some of the features of the great collective story that are embodied in the individual stories that make up the Australian Dictionary of Biography? How has the big story changed over the past half century? What are some of the external social and political events and shifts that might have influenced these changes? It is only now, with the ADB providing the tools to search digitally for themes, threads and patterns, that these questions can be explored in depth and to some extent answered with clear evidence rather than opinion - and begin to uncover or foreground specific assumptions that inevitably underlie any selection process that takes place under the heading of 'nation'. Blind spots can be made visible. $^{14}$

This paper takes the position that national biography, whether or not it sets out to do so, reflects how a nation views itself - in terms of its preoccupations, its values and its key historical events and people - its 'nationness'. ${ }^{15}$ In other words national biography and national identity are inextricably linked. To the extent that any kind of authoritative history influences collective views of the nation, national biographies also play a role in shaping that identity. In the case of the $\mathrm{ADB}$, whose processes are avowedly 'democratic', dominant values and interests are embedded not 
only in the text of individual biographies but in the patterns of selection of candidates for inclusion.

Biography, then, as it has been produced by the ADB, can provide wideranging evidence relating to Australia's evolving sense of itself as a nation. ${ }^{16}$ In addition, biography is a field that has particular contemporary relevance to digital publication and research methods. There are a number of reasons for this. First, in the digital arena, auto/biography is flourishing on a scale that was unimaginable in the past. There is no doubt that the daily entries of millions of people on personal blogs, Facebook, YouTube, and the many new forms of social media that have appeared in recent years can be seen as a global explosion of micro-auto/biographical expression. The massive popularity of family history research via websites such as Ancestry. com is part of the same burgeoning of biographical activity in the digital environment. Biography's intrinsic interdisciplinarity - historically an impediment to institutional recognition - is in its element in the digital world where disciplinary boundaries give way to unbridled connectivity.

The second reason is related to the structure of the biographical enterprise: biographers study the lives of individuals, not as isolated instances but as they function within collective social frameworks. This corresponds with the dual micro/macro analysis approach that is a feature of digital humanities research practices, where discrete exemplars operate within the framework of vast datasets. The bringing together of these approaches in biography - usually employed simultaneously in order to situate one person within a wider historical context - has been enhanced and extended by using computer assisted techniques including social network analysis. Focused as it is on the study of individuals in society, biography requires a combination of what is now often referred to in digital literary studies as 'close' and 'distant' reading. For biography close readings highlight the inevitably subjective and always individual nature of life experiences and courses. Looking from the 'distant' perspective, one life may indicate or reinforce wider patterns of experience, but alone can never be understood as properly representative of larger patterns. Private experience may correspond with broader social experiences, or may contradict them.

Third, the digital environment has created a space for developing experimental, hypertextual narratives that allow writers and producers of life stories to move away from the neat linearity of traditional print genres of biography towards the new kind of multidimensionality enabled by digital forms. This is a transformative change with major ramifications for the study of biography, identity and history.

Parallel transformative possibilities have opened up for the biography of a nation as for that of an individual in terms of both production 
and analysis. In particular, the aim here is to give preliminary consideration to how digital formats and tools can be used to cast light on the undeclared convictions and assumptions about Australian nationhood that have framed selection and prioritisation of subjects for inclusion in the national biography as well as the selection of material in the stories themselves. This is not to imply that the goal is to discover what has been referred to as the 'genetic code of the nation'. ${ }^{17}$ On the contrary, it is to gain a better basis for understanding that nations are forever changing as they are imagined and re-imagined and for tracing some of those changes.

In the case of the ADB the search for these convictions and assumptions has been made particularly challenging by the democratic, collaborative and decentred way that the ADB has been produced and by its explicit commitment not to seek to build or reinforce ideas of national identity. From the beginning, the ADB fended off the idea that it was a nation-defining project and has never in fact used notions related to national identity as criteria for selection of subjects. ${ }^{18}$ Nevertheless, readers see the ADB as a work that 'to a great extent ... describes and defines Australia', and so the way is open for aspects of the national culture to be lit up in fresh and possibly surprising ways.

The idea of a national story - or a series of stories - emerging from the multiple stories in the ADB is particularly relevant in Australia. As a former colony of Britain, with enduring ties of language and history with Britain and Europe, Australia has had a long history of working to create an identity of its own. Poets, painters, novelists, politicians, marketers and journalists have sought to capture, introduce, celebrate or reinforce characteristics that distinguish Australians from Europeans. In the late $19^{\text {th }}$ century, in the decades prior to Federation, there was a powerful patriotic tide of activity across the arts. As the influential novelist and essayist Vance Palmer wrote,

There has grown up a legend of the Australian nineties as a period of intense artistic and political activity, in which the genius of this young country had a brief and brilliant first flowering. Something new, it is claimed, emerged into the light. A scattered people with origins in all corners of the British Isles and Europe, had a sudden vision of themselves as a nation, with a character of their own. ${ }^{19}$

The effects of this 'flowering' can still be felt in the Australian selfimage. ${ }^{20}$ In his book Inventing Australia: Images and Identity 1688-1980 Richard White refers to the search for identity as a 'national obsession'. 'Most new nations', he writes, 'go through the formality of inventing a national identity, but Australia has long supported a whole industry of 
image-makers to tell us what we are'. ${ }^{21}$ How are these and other 'visions of themselves as a nation' reflected in the ADB's own vision and in the 'significant' Australian representatives that are assembled in its 'pantheon'? Consideration of these large questions requires an understanding of the practicalities of the ADB's production over its long history.

The ADB was a product of the founding commitment of the Australian National University to undertake projects of national importance. In 1957, Keith Hancock, then professor and inaugural chair of history and director of the Research School of Social Sciences at the ANU, had brought together Australian historians at a conference with representatives from all Australian universities, intended to assess the 'state of Australian History' and initiate collaborations..$^{22}$ Resources for the study of Australian history at that time had major gaps, of which a national biographical project was one. Hancock had been involved in the British Dictionary of National Biography and argued that Australia, and the ANU, needed a biographical project of similar national significance and scale. Prior to the formal establishment of the ADB, a Biographical Register (initially called the 'National Register') was started in 1954 by Laurie Fitzhardinge. ${ }^{23}$ The project gathered information about 'significant Australians', and was to form a research resource from which subjects could be selected for inclusion in the dictionary. An ADB Editorial Board met for the first time in 1960. ${ }^{24}$ In 1962 Hancock argued the ANU should fund the position of General Editor as well as research positions to enable production of the dictionary. ${ }^{25}$ The local organisational and national governance structures have remained largely intact since that time.

Representativeness has been a central consideration throughout the history of the ADB. A promotional poster produced circa 1992 by Melbourne University Press to advertise the first 12 volumes of the ADB and index was titled 'Australians All'. ${ }^{26}$ These are the first two words of the Australian national anthem that replaced 'God Save the Queen' in 1984 and the message was clear: this is a resource that reflects the pride of Australia in its people and their achievements - Australians all:

\footnotetext{
...explorers, teachers, artists, politicians, lawyers, nurses, farmers, clergy, soldiers, actresses, engineers, poets, circus proprietors, shearers and bushrangers are among the 7000 individuals whose lives are contained in the Australian Dictionary of Biography....Their biographies, set in the period they flourished, are available in a series of twelve volumes.... ${ }^{27}$
}

However extensive and varied the list may be the questions still remain 'how are they representative?' and 'how did they qualify to have a biography written of them'?28 These in turn relate to fundamental questions 
posed or implied in any biographical enterprise, including "what represents a life?' and, for national projects, 'what represents a nation?' What kinds of people should be in the dictionary? To what extent does the process of selection inform the overall character of a work, and in turn what agency does this have in producing commonly held ideas about national character? Should the selection of biographical subjects in a national dictionary be linked with notions of national identity and if not what other options are there? As the first part of this paper has touched on, there are multiple ways of approaching both the concept of nation and of representativeness, and while representativeness may be a goal, it can only be achievable in limited ways and under defined categories, which themselves may not be representative of 'all Australians'. The current general editor of the ADB makes the point:

The ADB is hardly representative. It has been estimated that nine million Australians died between 1788 and 1990. Given that 12500 dictionary entries cover this period, any single person has 0.1 per cent chance of 'getting into' the ADB. ${ }^{29}$

Through its subjects, the ADB presents the story of Australia's interactions with the outside world as well as its 'internal' ideas of nationhood. In the context of this article in the European Journal of Life Writing, it is significant to see that a simple word search for 'Europe' shows that it appears 1495 times. This means that over 50 years, on average, there are only about 30 references to Europe each year over many thousands of entries. Clearly this does not adequately reflect the deep ties between Europe and Australia that the dictionary itself shows in other ways, including through the selection of its subjects. In today's multicultural Australian society, according to the national census in 2011, more than a quarter of the population are born outside of Australia and a further $20 \%$ have at least one overseas-born parent, with many historically coming from Europe, especially in the waves of migration caused by displacement following wars in the 20th century. ${ }^{30}$ This observation about the use of a single word raises questions that invite further research, including changing notions of 'Europe' over half a century and how these might be reflected in the ADB.

Not surprisingly there is a European focus in early volumes of the ADB as a result of Australia's historical situation as a British colony and, as its resistance to becoming a republic demonstrates, its colonial origins continue to play a role in contemporary Australia's sense of itself. ${ }^{31}$ In the $\mathrm{ADB}$, tracking references to Britain and England can enable trends in the strength of this allegiance to be analysed and mapped against relevant 
historical events leading to, for example, Australia's 1999 referendum on the formation of a republic. While historical ties with Europe remain strong, so too do links with Asia and other parts of the world. Many entries on Chinese subjects in the ADB, for example, were centred on the time of the Victorian gold rush from 1850, when Chinese entrepreneurs brought new produce and trade. They were included in the ADB on the basis of their mercantile or community building contribution; few had found gold.

In designing the ADB in the $1950 \mathrm{~s}$, the founders put in place processes aimed at achieving a balance of representation in the selection of lives documented in the early volumes. The policy was to choose 'representative people, ${ }^{32}$ or what was referred to by the general editor in Volume 1 of the dictionary, as 'samples of the Australian experience'. ${ }^{33}$ A later general editor, speaking in the 1980 s, estimated that 5-10 per cent of subjects fell in the category of being 'representative' samples of an era, and that this was especially so in the period from 1788 (Australia's European settlement) to the mid- $19^{\text {th }}$ century (the start of the gold rush era). ${ }^{34}$ Recently the current general editor has described the $\mathrm{ADB}$ as 'generally representative, rather than directly representative'. ${ }^{35}$ A subject need not have been born or even spent long in Australia to be selected for the ADB. But what does it mean to be 'generally' rather than 'directly' representative? - and representative of which population segments or cultural aspects of Australia? Analysis of the actual choices made are bound to cast light on the implicit criteria that drove idea of representation at particular times.

Formally, the selection process relies on a system of nomination by working parties in the states and territories of Australia. ${ }^{36}$ The proportional representation of each of Australia's six states (taking into account relative population growth) was an early guiding rule that has been maintained with few modifications to this day. The number of biographical subjects differs by geographical area and continues to be calculated in proportion with state populations (based on a weighted formula, using Australian Bureau of Statistics census figures). Thus the states with the largest representation are New South Wales and Victoria. The system was introduced in its current form in the $1970 \mathrm{~s},{ }^{37}$ but there has always been discussion over appropriate levels of state representation and this informed the earlier volumes. While ordered by period and alphabetically following a long term plan, the impression (from some reviewers at least) remained that the $\mathrm{ADB}$ was a miscellany that nevertheless benefited from lack of over-design. ${ }^{38}$ Quotas are based on historical demography and available statistics relating to each period, but other policies have influenced representation at different times. 
In 1991 a separate print index was published, corresponding with 379 selected categories of occupation and allowing the dictionary to be 'read' in new ways. ${ }^{39}$ The digital transformation of the ADB from 2006, when it moved online, involved incorporating information from the index and more recently it has included the development of web-based tools for analysis. This has allowed advanced analysis including visualisation of the many facets of representation in the dictionary. In providing the capacity to see the relative proportions of people in various occupations, this analytical tool is again fuelling the discussion around who should be included in the future. The large number of 'pastoralists' included in the past, for example, suggests broad acknowledgment of the importance of that category in Australia's history, while other occupations, though long established, do not appear at all. I understand that the dictionary is still trying to include a 'tatooist', for example. We have the opportunity now to explore the role that categories of occupation have played in the quest for 'general' representativeness.

In the early days of the ADB there was little consideration given to 'balance' in terms of gender or inclusiveness in terms of ethnicity. Attitudes were very different then and the principles underlying selection can now be researched very efficiently with digital tools. The criticisms over 'group omissions', which have focused on women, Aborigines, and 'the working class' have also implied over-representation of other categories. The large number of military entries was justified on the grounds of Australia's involvement in WWI in particular but extends to other war contexts. ${ }^{40}$ While not explicitly seeking to represent Australian identity in terms of war service, the ADB's emphasis has this effect.

The fact that overall word length of the print volumes could not be substantially extended undoubtedly influenced selection. ${ }^{41}$ Even when the ADB was published in digital form, removing cost restrictions imposed by the print volume, policies continued to dictate that the allocated word limits not be extended. Relative word length continues to be indicative of a subject's perceived importance or significance - a choice which is in the hands of the state based working parties. ${ }^{42}$

Now that the dictionary has been published continuously for more than half a century, new questions are becoming relevant, such as, 'How can we understand the selection of subjects over time historically, in the context of the era in which each volume was produced?' and 'what does this reveal about changing attitudes in Australia and in the academic community?' And even more specifically, 'Is selection bias a cumulative problem and if so is it possible to redress over time?' Thinking ahead, 'Is it ever possible to avoid selection biases and should this be a goal?' or rather, 'Should selection biases be explicitly foregrounded in the context 
of changing ideas of nation?' In this context the ideas of 'representativeness' and 'balance' invite investigation with the help of digital tools.

The topic of representation is especially significant to look at through digital means because it has been the point on which the dictionary has most often been criticised. ${ }^{43}$ The numbers of biographical subjects who were women, Aborigines or those in particular occupation categories could all be identified through the printed lists and records of the ADB, but that information was not easily seen and publicly available until presented online. Now the ADB provides a tool to analyse these issues. ${ }^{44}$ The analysis of various categories in certain periods of the dictionary and eras in Australian history, provides a sobering view of gender balance: for example, $88 \%$ of ADB subjects are men. Women reached a record of 14 per cent representation by volume 14 and the figure now sits at 14.3 overall. ${ }^{45}$ It would seem that a wholesale re-write of the dictionary would be required in order to rectify this imbalance.

The low representation of women and Aboriginal subjects in ADB volumes over time ${ }^{46}$ was a large part of the rationale for a 'missing persons' supplementary volume published in 2005. This strategy had been tried by other dictionaries. Women and Indigenous people were among the 500 entries added to the ADB through the supplement. The timeframe the supplement covered was also extended, so that the first-born subject in the ADB was now the Dutch explorer Dirk Hartog (b.1580):

\footnotetext{
Regarding Indigenous history, for reasons outlined earlier, the supplement proved timely. Thanks to its suitably extended time span, 1580-1980, and the opportunity to take in new biographical research, the volume was able to include 49 Indigenous biographies, 10 per cent of total entries in the volume, for which the various working parties are to be highly commended. At present, an estimated average of 1.9 per cent of all entries in the $A D B$ are for Indigenous Australians. ${ }^{47}$
}

The working parties in each state decided who had been missed out looking at class, race and gender. There is much information available now, especially via digital means, that would not have been available previously to working parties and so the selection process can be better informed. However, because producing the supplementary volume cut across all the painstaking usual deliberations about selection, it was controversial. The notion of a supplementary volume is closely linked to the print world. Now that all ADB entries from all previous volumes are combined in the one digital resource or online edition, those articles in the supplementary volume are folded in with the rest. The effect is a relatively small but nevertheless significant statistical improvement in the overall representation of particular groups. But there are other areas that 
need attention too. Regularly noted now, for example, is the omission of Irish and over-representation of Scottish. ${ }^{48}$ Also, a simple text search of ADB online (a process impossible without the computer) shows that the term 'homosexual' appears only 19 times, a startlingly low figure that McGinness draws attention to, noting that 'to identify some 20 men out of 10500 as homosexual does seem rum' but also pointing to the fact that sexuality of subjects was not a focus in biography until the second half of the 1960s. ${ }^{49}$ McGinness cites a speech by general editor of the Dictionary of National Biography in the mid-1990s, noting that including the sexual life of subjects in that dictionary was 'perhaps the central challenge'. ${ }^{50}$

Within any volume there were selection biases that reflected the choices made in a particular era by past working parties and these, in turn, inescapably reflected contemporary views of Australia. There is no doubt that individual volumes aspired to 'balance' and consistency, but these terms themselves take on different meanings in different political and social environments. Now that all the volumes have effectively been thrown in together online, some of the contextual understanding that would come with reading individual volumes is removed. They are now accessed as part of the very large and alphabetically ordered online aggregate of total volumes. What is referred to by a past deputy general editor as a 'digital soup' is the outcome of that mixing. ${ }^{51}$ An advantage of this is that notions of balance and consistency as they were applied over the whole project, viewed as a single work, can be made visible and explored. A degree of inconsistency was earlier introduced when the floruit principle (of choosing biographical subjects in terms of 'the period in which they were deemed to have made their major impact on Australian history'52) was formally replaced by the ordering principle of date of death from Volume 13. The notion of being 'set in the period they flourished' had been enabled through the context of each individual volume, which covered a period of time and had a preface with introductory remarks that set the collection of entries in the context of the era and in some cases commented directly on the selection of articles. ${ }^{53}$ The basis of selection for the first two-thirds of the print volumes is at odds with subsequent volumes, introducing a further element of inconsistency overall and drawing the ADB 'perilously close to the present', as the current general editor puts it. ${ }^{54}$

All this is not to say that articles cannot still be consulted by volume it is possible to browse by volume by clicking on links that aggregate the data in this way. However, most readers now arrive at an entry via a web search, rather than holding the volume and considering that article in the context of others. Arguably a disadvantage in terms of historical contextualisation, this is also a clear benefit in terms of easy access. And yet, 
the online version of the dictionary can help to reunite, as it were, subjects who may have made their notable contribution in the same era or even as an identified group, by allowing these entries to be grouped and read as a collection through advanced indexing. ${ }^{55}$

\section{CONCLUSION}

The ADB's digital tools are giving researchers a fuller view on the total content of the dictionary, and the way it has developed over time. This is particularly relevant to the discussion of representativeness and the role of a national biographical resource in framing the context of particular eras of history in terms of their social trends and demographics. Australia has experienced a dramatic population increase during the time the ADB has been produced and to which the volumes refer. Australia's population reached about 4 million in 1900, and it was from this total that subjects in the early volumes were chosen. Now that it has reached over 20 million, it is clear that the task of selection of entries in the second half of the $20^{\text {th }}$ century became increasingly more difficult, even though the overall word count had been raised over time. ${ }^{56}$ The ODNB chose the number 50000 articles (featuring 55113 lives) to represent 'a sensible marker, not the sum total, of British history'. ${ }^{57}$ The ADB currently has close to 13,000 lives, but it covers a vastly reduced time frame and from a much smaller population base. Former general editor John Ritchie compared the ADB with the British $D N B$, noting the ADB could be charged with being 'less discriminating' but was 'more democratic'. ${ }^{58}$

More significant for the future is the range of demographic groups that are to feature in the next 'period' (10 years of deaths). While the dictionary is only now editing new articles relating to deaths in the early 1990 s, it is only 'behind' the present time by about 15 years - a very short time to take stock of the achievements of 'Australians all'. For the first time, ADB is now publishing online the list of future subjects, with the current 'Period 6' list covering nominated subjects who died in the period 1991-2000. But the process of nominating key people has not changed. There are $14 \%$ Indigenous people in the coming period, for example, indicating a small step in the direction of righting the 'balance'.

Reflecting on the choice of image for the front cover dust jacket of Volume 18 of the ADB (the last print volume, published in late 2012), general editor Melanie Nolan emphasised that it evokes the diversity of subjects in the new volume (covering the 1980s, subjects $\mathrm{L}-\mathrm{Z}$ ) and also of the influence of new technology in producing volume 18, the first to be published simultaneously in print and online. ${ }^{59}$ In this sense the 
image pointed to changes other than simply moving the resource from print to digital. The project was reconceptualised as a digital environment in which to work with and analyse the collection. That there is free public access to the online edition indicates that the dictionary has remained true to its democratic principles in this regard. In a review of the ADB in 1967, historian Geoffrey Blainey commented that 'someday some of its adherents will probably use the dictionary to compute the importance of such types as London men, ex-servicemen, young men, in shaping early Australia'. ${ }^{60}$ Blainey refers to computing but it is not in the modern usage. Blainey's comment reinforces the commonly held view that the 'types' that populate the ADB hold the key to the 'shaping' of Australia. The kind of analysis he imagines would have been extremely difficult to achieve prior to modern computing. Surprisingly, despite the new utility, 'The challenge faced by editors and publishers is to persuade readers, even those comfortable with online research, that resources like the $A D B$ and $O D N B$ online offer more than the print edition on screen'. ${ }^{61}$

The ADB's plan for the next stage of the evolution of the dictionary is already underway, with intensive indexing of articles and publication of metadata to accompany them allowing the drawing of computer generated family trees and even social network graphs showing spousal relations and tiers of familial connections. This is precisely to allow researchers to manipulate the data that underpins the dictionary, including to 'compute the importance' of figures in the dictionary based on seeing their influence and interrelation with other biographical subjects, as well as discovering other patterns. This will enable reading 'the nation' in terms of following flows, cross-currents, tides and influences - navigating, and discovering in ways that question notions of national identity rather than consolidating them.

In spite of its centrality in popular culture, biography as an academic field continues to occupy an uneasy place in university departments. Crossing history, literature, and many other disciplines, it is often considered to be too historical for literary study, too literary for historical study, and on the margins of other areas. In the digital environment, however, biography has a very high profile, with its generically ambivalent and interdisciplinary nature lending itself perfectly to digital forms of expression and communication. In many ways it can be seen as a demonstration of biography's greatly increased capacity, in the digital era, to activate cross-disciplinary investigation, and become a dynamic agent for integrating and connecting individual lives and their historical contexts.

In the case of the ADB, the ease with which 'Australians all' can enter and explore this 'literary pantheon', means that there are new possibilities 
for reviewing Australia's past sense of nation-ness - who we believed we were, as revealed by the miscellany of lives it contains - as a basis for imagining who we might become.

\section{ABOUT THE AUTHOR}

Paul Arthur is Professor and Chair in Digital Humanities at the University of Western Sydney. He was previously Deputy Director of the ANU Centre for European Studies, a joint-funded special initiative of the European Commission and the Australian National University. From 2010 to 2013 he was Deputy Director of the National Centre of Biography, ANU, and Deputy General Editor of the Australian Dictionary of Biography. A Fellow of the Royal Historical Society, he has published widely in fields of cultural studies, communication, history, literature and media, and has held visiting appointments in Europe, North America and Australasia.

\section{NOTES}

1 Dr Dawn Casey PSM FAHA, is the Chair of the Australian Indigenous Land Corporation. She is a highly respected Indigenous Australian who was appointed Director of the Museum of Applied Arts and Sciences (Powerhouse Museum) in 2008. Quoted on the ADB website http://adb.anu.edu.au/adb-comments/ accessed 30 March 2014.

2 Her Excellency Penelope Wensley AC, Governor of Queensland since 2008. Quoted on the ADB website http://adb.anu.edu.au/adb-comments/ accessed 30 March 2014.

3 Benedict Anderson, Imagined Communities: Reflections on the Origins and Spread of Nationalism (London: Verso, 1991 [1993]), 5, 6.

4 11,745 biographies in Volumes 1-18 and further entries being continually edited.

5 Quotation from dust cover of Volume 18.

6 Professor the Hon Gareth Evans AC QC, quoted on dust cover of Volume 18.

7 Each entry in the dictionary is written by a commissioned author. Once their original submission is received and processed, it enters an editing process that takes three months on average. It involves a sequence of internal editing, checking and review, by an assigned research editor, the general editor, and the managing (deputy general) editor, followed by external review, and author feedback on the changes made.

8 The Hon. Barry Jones, AO made the comment: 'The Australian Dictionary of Biography is our greatest collective research project in the humanities and a national triumph. We have much to learn from it. The project is continuing to change as we mature nationally, with deeper understanding about the impacts of gender, race, environment, religion, education, language, culture, politics, region and war on what we are and what we may become'. Quoted on the ADB website http://adb.anu.edu.au/adb-comments/, accessed 30 March 2014.

9 Benedict Anderson makes the point that 'Communities are to be distinguished, not by their falsity/genuineness, but by the style in which they are imagined'. If it is accepted that the nation is an imagined community, then the 'style' of a national enterprise such as a dictionary of biography, representing 'all Australians', can be said to 'distinguish' the community that is Australia (from other communities), with the 'style' of imagining covering selection of content as well as form. Anderson, Imagined Communities, 6 . 
10 Fredric Jameson quoted in Robert Young, White Mythologies: Writing History and the West (London: Routledge, 1990), 113.

11 Homi Bhabha, The Location of Culture, Routledge, London, New York, 1994, 142.

12 Fredric Jameson, "Third World Literature in the Era of Multinational Capitalism," Social Text, no. Fall (1986): 69.

13 Graeme Turner, National Fictions: Literature, Film and the Construction of Australian Narrative, Allen \& Unwin 1993, 19.

14 On the matter of blind spots, Eve Kosofky Sedgwick makes a similar point in relation to the term 'America' as it was used at a conference on 'Liberal Arts in the Twentieth Century': "What was disturbing me then the term 'America' had come, unbidden, and unremarked, to occupy a definitional center for almost every single one of the papers, and for the conference as a whole, in a way that no one could even seem to make visible enough to question. That the conference, whose title did not specify 'America', and whose topic was by no means necessarily circumscribed by any boundaries of the national, had lined up so neatly in the current train of contestations about what exclusive or inclusive, white or non-white, gay or straight, homogenous or heterogeneous visions are to constitute a national culture, a national identity, about where we are to look for the special American values - be they good or bad - of America and American education, seemed a striking datum to the very degree that it was taken for granted. Eve Kosofky Sedgwick, 'Nationalisms and Sexualities in the Age of Wilde', in Andrew Parker, Mary Russo, Doris Summer, and Patricia Yaeger, Nationalisms and Sexualities, Routledge, New York and London, 1992, $235,236$.

15 See Anderson, on 'emblems of nation-ness' in Anderson, Imagined Communities, Imagined Communities, 133.

16 An interesting parallel can be found in Australia's Macquarie Dictionary. On the Australia Day weekend 2014, in his article headlined, 'Dictionary helps celebrate being an Australian', Zoltan Kovaks writes, "It [Australian English] was hard to define but easy to recognise....It [the Macquarie Dictionary] was first published in 1981 as a dictionary designed to record how Australians used the English language. Its compilers did not do so with any sense of belligerent nationalism, but sought merely to present a comprehensive professional account of Australian English". Zoltan Kovaks, The Weekend West, Agenda section, February 1-2, 2014, 74.

17 Homi Bhabha, ed., Nation and Narration (London and New York: Routledge, 1990), 2.

18 Melanie Nolan, "'Insufficiently Engineered': A Dictionary Designed to Stand the Test of Time?," in The ADB's Story, ed. Melanie Nolan and Christine Fernon (Canberra: ANU E Press, 2013), 21. A decision made in 1960.

19 Vance Palmer, The Legend of the Nineties (South Yarra, Victoria: Currey O'Neill, 1954), 1.

20 The Bulletin journal was instrumental in propagating a sense of independent Australian national identity. Richard White, Inventing Australia: Images and Identity 1688-1980 (Sydney: Allen and Unwin, 1981) especially Chapter 7: 'Young, White, Happy and Wholesome', 110-24.

21 Richard White, Inventing Australia: Images and Identity 1688-1980, George Allen and Unwin, Sydney, London, Boston, 1981, viii.

22 Nolan, "Insufficiently Engineered'," 16, 43.

23 Ibid., 5. Fitzhardinge (1908-93) was a librarian, classicist and Australianist working at the National Library as a research officer from 1934. Ann Moyal, "Sir Keith Hancock: Laying the Foundations, 1959-1962," in The ADB's Story, ed. Melanie Nolan and Christine Fernon (Canberra: ANU E Press, 2013), 49.

24 Nolan, "'Insufficiently Engineered'," 5.

25 Ibid.

26 Reproduced in Ibid., 6. The original source for the image is noted as ' $A D B$ archives'. 
27 Cited in Ibid.

28 Melanie Nolan, "Preface," in Australian Dictionary of Biography Volume 18: 1981-1990, ed. Melanie Nolan (Melbourne University Press, 2012), vi. Melanie Nolan, "Insufficiently Engineered': A Dictionary Designed to Stand the Test of Time?," in The ADB's Story, ed. Melanie Nolan and Christine Fernon (Canberra: ANU E Press, 2013), 23. See also Ibid.

29 Nolan, "'Insufficiently Engineered'," 23.

30 See http://www.abs.gov.au/ausstats/abs@.nsf/Lookup/2071.0main+features902012-2013.

31 At a referendum on November 6, 1999, Australians voted 55\% to $45 \%$ against a proposed model to make the nation a republic. The vote was the culmination of a debate that has lingered throughout Australian history, but which gathered momentum following the dismissal of the Whitlam government in 1975, and moves by Prime Minister Paul Keating in the 1990s. See http://australianpolitics.com/topics/republic, accessed 30 March 2014. Also, at the time of writing, Australia's Prime Minister, Tony Abbott, has this week suddenly reinstated knighthoods after they had been abolished (and intermittently reappeared) several decades ago in favour of Australian Honours, thus symbolically strengthening Australia's traditional links with Britain.

32 Nolan, “'Insufficiently Engineered'," 22. This does not, by any means, guarantee or even promote full coverage of occupation categories. There is not yet a tattooist in the dictionary, but when there is the occupation category schema will simply be expanded to cover this and other new additions. Subjects can also be listed under multiple occupation categories if they achieved prominence or notoriety in more than one.

33 Douglas Pike, "Preface," in Australian Dictionary of Biography Volume 1 (Carlton, Victoria: Melbourne University Press, 1966), v. Cited in Nolan, "Insufficiently Engineered'," 22.

34 John Ritchie, "Talk to the New Dictionary of National Biography, Ritchie MSS, Box 2, Acc 06/191" (National Library of Australia, October 9, 1999).

35 Nolan, "Preface," vi.

36 There are six states: Victoria, South Wales, Tasmania, Queensland, South Australia, Western Australia and 2 territories: Australian Capital Territory and Northern Territory.

37 Jill Roe, "National Collaboration: The ADB Editorial Board and the Working Parties," in The ADB's Story, ed. Melanie Nolan and Christine Fernon (Canberra: ANU E Press, 2013), 283. Citing Paul Brunton, "Mysterious Quotas," Australian Book Review, no. February (2006): 19-20.

38 Nolan, "'Insufficiently Engineered'," 22.

39 Melanie Nolan, "From Book to Digital Culture: Redesigning the ADB," in The ADB's Story, ed. Melanie Nolan and Christine Fernon (Canberra: ANU E Press, 2013), 385.

40 Nolan, "Insufficiently Engineered'," 23, 24. Nolan notes claims that elite, military, and NSW people have been over-represented.

41 It should be noted, however, that even the overall word allocations in the print volumes have not stayed the same. Volume 7 contained a third more pages and a quarter more entries than volumes 3 to 6 . Ibid., 29. Nevertheless, the principle of allocation remained. These observations show the possibilities open for computing-enabled forms of analysis as much as they do the areas where such options are effectively closed. The potential to have a longer overall word length does not mean it should be taken up.

42 And yet, while word length of articles is intended to indicate relative significance, in practice some prominent lives can be quickly summarised whereas others, perhaps less visible, need more explanation. See John Tregenza, "Working Parties: Recollections of the South Australian Working Party," in The ADB's Story, ed. Melanie Nolan and Christine Fernon (Canberra: ANU E Press, 2013), 224.

43 Nolan, "'Insufficiently Engineered'," 23.

44 See http://adb.anu.edu.au/stats/site. 
45 Nolan, "Insufficiently Engineered'," 25. Mark McGinness, "Assessing the ADB: A Review of the Reviews," in The ADB's Story, ed. Melanie Nolan and Christine Fernon (Canberra: ANU E Press, 2013), 308. The percentage of women has also been reported as reaching 20 per cent in volumes 13-14, but then declining once more. See Geoffrey Bolton, "John Ritchie: Consolidating a Tradition, 1987-2002," in The ADB's Story, ed. Melanie Nolan and Christine Fernon (Canberra: ANU E Press, 2013), 169. ADB research editor Karen Fox, in her research on the history of fame, is comparing what other biographical projects on the national level, as well as related systems, such as the honours system, have used in terms of selection processes - and whether they have used quotas or not, to ensure representation of key groups, including of women. Honours for women, she found, in 1920 Australia, were only $20 \%$ - but this also reflects opportunities for women to enter fields and achieve in public life. It is not simply the case that there should be equal honours allocations for women at all times.

46 See Nolan, “Insufficiently Engineered'," 26.

47 Roe, "National Collaboration," 291. The note on the same page reads: The average for the most recent volumes - ADB Volumes 13-17 plus the supplement - is 3.6 per cent. Material presented to ADB 2009 seminar by staff, copy courtesy Darryl Bennet.

48 Nolan, "Insufficiently Engineered'," 26.

49 McGinness, "Assessing the ADB," 310.

50 Colin Matthew, "Dictionary of National Biography," in National Biographies and National Identity, ed. Iain McCalman, Jodi Parvey, and Misty Cork (Canberra: Humanities Research Centre, Australian National University, 1996), 11. Cited in McGinness, "Assessing the ADB," 311.

51 Nolan, "Insufficiently Engineered'," 27.

52 Bolton, "John Ritchie," 162.

53 McGinness, "Assessing the ADB," 303. An example given is the preface to Volume 7, which noted the trend to wider inclusion.

54 Nolan, "Insufficiently Engineered'," 29. The current policy is for a minimum of ten years from date of death. Roe, "National Collaboration," 284.

55 Nolan, "Preface," viii.

56 Bolton, "John Ritchie," 168.

57 Philip Carter, "Opportunities for National Biography Online: The Oxford Dictionary of National Biography, 2005-2012," in The ADB's Story, ed. Melanie Nolan and Christine Fernon (Canberra: ANU E Press, 2013), 349.

58 Ritchie, "Talk to the New Dictionary." Cited in Bolton, "John Ritchie," 168.

59 Nolan, "Preface," v, viii.

60 Geoffrey Blainey, "The Australian Dictionary of Biography," Papers and Proceedings [Tasmanian Historical Research Association] 15, no. 2 (November 1967): 58-64. Reprinted in McGinness, "Assessing the ADB." Quotation from page 26.

61 Carter, "Opportunities for National Biography Online," 353. 